\title{
Dural tear repair surgery comparative analysis: a stitch in time saves nine
}

\author{
Charles Taylor ${ }^{1}\left[\right.$ (]) Amad Khan ${ }^{2} \cdot$ Emad Shenouda $^{2} \cdot$ Nicholas Brooke $^{2} \cdot$ Ali Nader-Sepahi $^{2}$
}

Received: 6 July 2021 / Revised: 14 October 2021 / Accepted: 29 November 2021 / Published online: 10 December 2021

(c) The Author(s) 2021

\begin{abstract}
Purpose A dural tear is a common iatrogenic complication of spinal surgery associated with a several post-operative adverse events. Despite their common occurrence, guidelines on how best to repair the defect remain unclear. This study uses five post-operative outcomes to the compare repair methods used to treat 106 dural tears to determine which method is clinically favourable.

Methods Data were retrospectively collected from Southampton General Hospital's online databases. 106 tears were identified and grouped per repair method. MANOVA was used to compare the following five outcomes: Length of stay, numbers of further admissions or revision surgeries, length of additional admissions, post-operative infection rate and dural tear associated neurological symptoms. Sub-analysis was conducted on patient demographics, primary vs non-primary closure and type of patch. Minimal clinically important difference (MCID) was calculated via the Delphi procedure.

Results Age had a significant impact on patient outcomes and BMI displayed positive correlation with three-fifth of the predefined outcome measures. No significant difference was observed between repair groups; however, primary closure \pm a patch achieved an MCID percentage improvement with regards to length of original stay, rate of additional admissions/surgeries and post-operative infection rate. Artificial over autologous patches resulted in shorter hospital stays, fewer readmissions, infections and neurological symptoms.

Conclusion This study reports primary closure \pm dural patch as the most efficient repair method with regards to the five reported outcomes. This study provides limited evidence in favour of artificial over autologous patches and recommends that dural patches be used in conjunction with primary closure.

Level of evidence I Diagnostic: individual cross-sectional studies with consistently applied reference standard and blinding.
\end{abstract}

Keywords Dural tear $\cdot$ Incidental durotomy $\cdot$ Primary closure $\cdot$ Dural patch

\section{Introduction}

A dural tear, also known as an incidental durotomy, refers to when the outer most layer of the meninges, the dura mater, is torn [1]. Dural tears most commonly occur as a complication of spinal surgery and patients who sustain a dural tear often recover well and do not commonly require further intervention following repair of the defect $[2,3]$. However, patients may complain of low-pressure headaches, photophobia and

Charles Taylor

ct1g17@soton.ac.uk

1 Faculty of Medicine, University of Southampton, Southampton General Hospital, Southampton, UK

2 Department of Neurosurgery, Southampton General Hospital, Southampton, UK nausea $[1,4,5]$. More serious consequences of poorly managed tears include meningitis, arachnoiditis and the development of pseudomeningoceles $[1,4,5]$. Therefore, further research to better define the management of dural tears may have beneficial clinical outcomes.

Despite the common occurrence of this complication, there are currently no definitive guidelines on how to best to manage an intraoperative tear [4]. Consequently, patient outcomes vary on a case by case basis [4]. This may be in part due to the inconsistent and varied methods of repair that surgeons use along with the absence of high quality comparative data $[4,6]$.

This retrospective study identifies 106 patients who sustained an intraoperative dural tear in Southampton University General Hospital, in either the Orthopaedic or Neurosurgery departments between 01/01/2016 and 04/11/2019. This 
study consequentially compares the method of dural repair against five primary outcome measures; length of hospital stay, length of additional admissions, numbers of further admissions or revision surgeries, post-operative infection rate and dural tear associated neurological symptoms. Subanalysis was conducted regarding patient age and body mass index (BMI) as well as against primary vs non-primary closure and artificial vs autologous patches.

\section{Methods}

$\mathrm{H}_{1}$ With respect to the studies five predetermined outcome measures, primary closure is the most advantageous form of repair for intraoperative dural tears.

$\mathrm{H}_{0}$ With respect to the studies five predetermined outcome measures, primary closure is not the most advantageous method of dural tear repair.

Data were collected from Southampton General Hospital's online 'surgery complications' 'Charts' and 'E-documents' databases. All patients with the terms 'Dural Tear', 'CSF Leak', 'durotomy' or 'pseudomeningocele' in their records were identified and later included in the study if it could be confirmed that they sustained an intraoperative dural tear from the Orthopaedics or Neurosurgery department between the 46-month period (Fig. 1). To ensure all relevant patients were included, the term 'dural tear' was entered into the main patient database search-bar and patients were cross-searched.

The following patient information was recorded; age at the time of surgery, BMI, title of procedure in which the tear was sustained, length of original stay, character of dural complication, method of repair, post-operative neurological symptoms, infection rate, readmission date(s), readmission procedure(s), duration of readmission(s) (Table 1). Patients were grouped per the method of repair used so that no patient appeared in more than one group (Table 2).

\section{Statistical analysis}

All statistical analysis was conducted on SPSS (IBM Corp. Released 2019. IBM SPSS Statistics for Windows, Version 26.0.). Minimal clinically important difference (MCID) was calculated for the primary repair analysis and for the artificial vs autologous patch analysis. MCID was calculated via the Delphi method amongst resident neurosurgeons to enable a formal consensus to be developed.

\section{Delphi procedure}

Four resident neurosurgeons were provided with a tworound Delphi survey. In the first round, surgeons were provided with information regarding the study and independently suggested MCID values for each outcome. In the second round, surgeons were provided with the group ranges and medians and their own answers so they may adapt their decisions. $100 \%$ consensus was achieved
Fig1 Flow diagram outlining patient screening for study inclusion
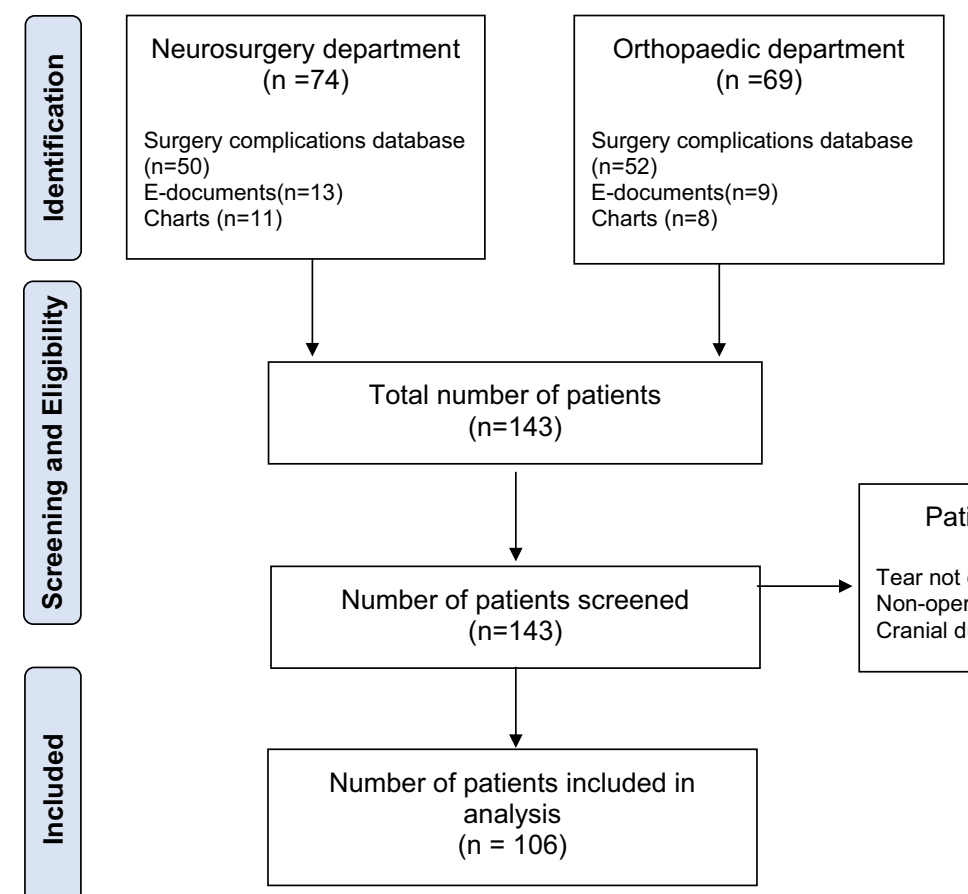

Patients excluded $(n=37)$ Tear not confirmed $(n=23)$ Non-operative tear $(n=8)$ Cranial dural tear $(n=6)$ 


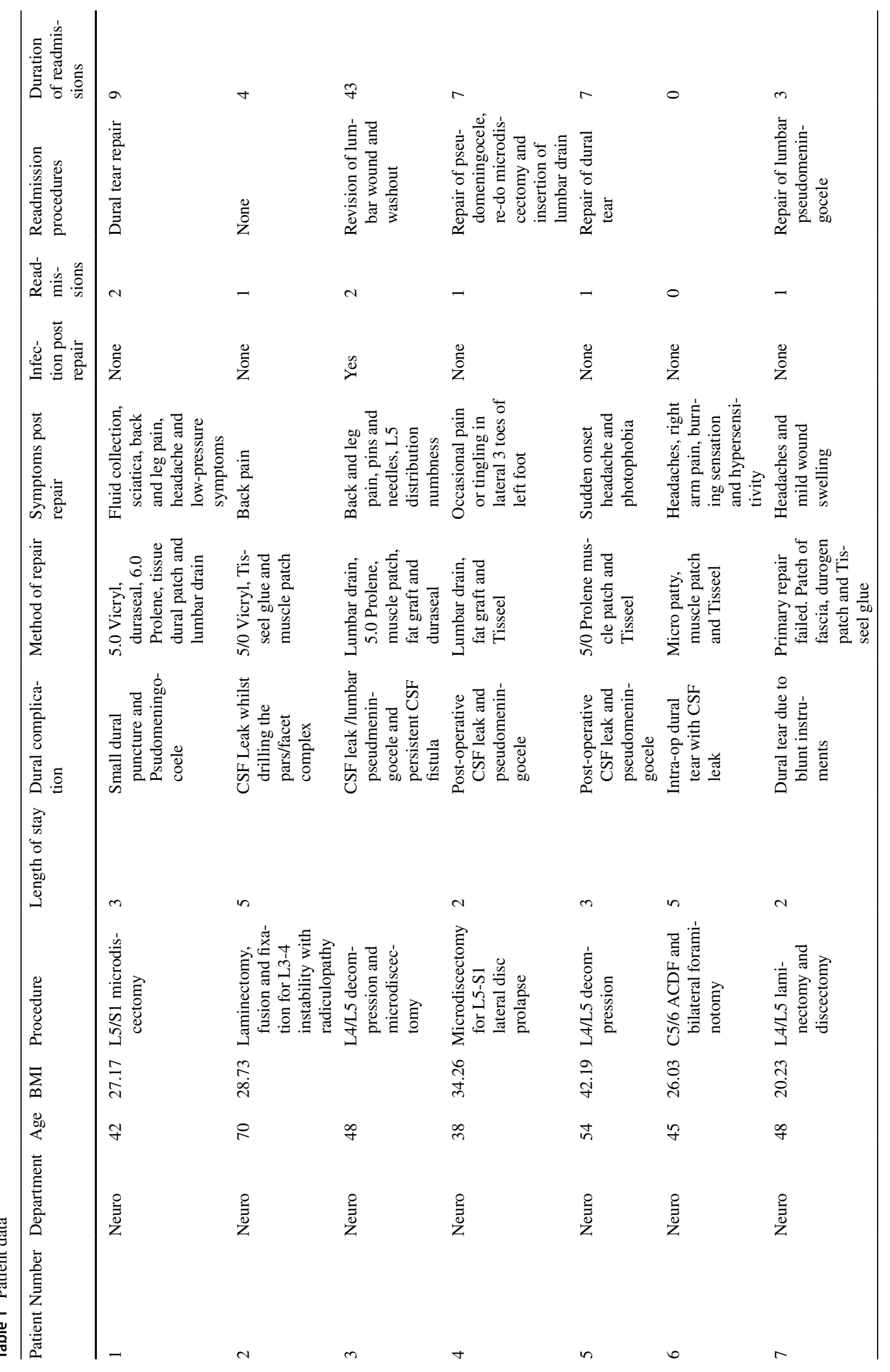




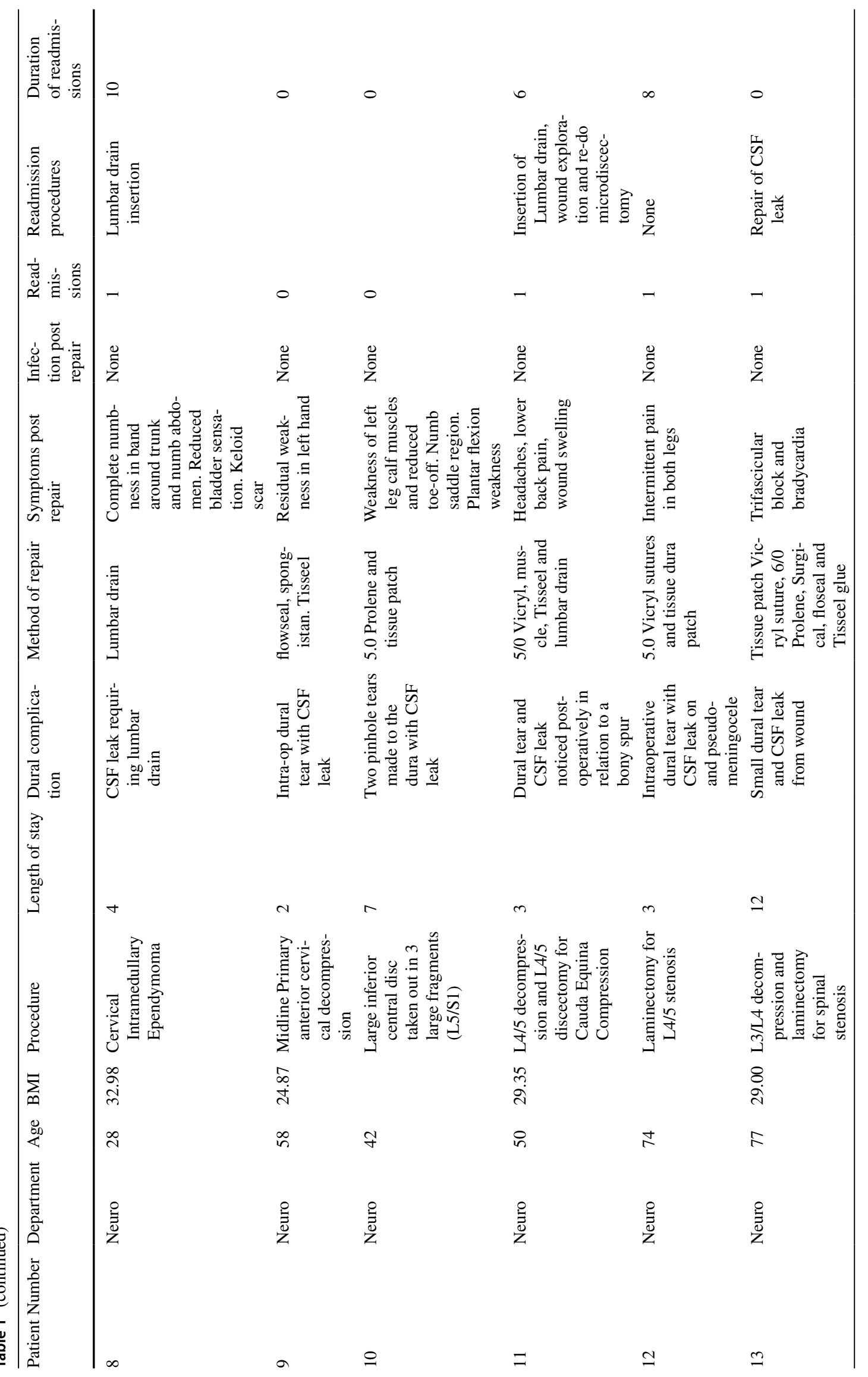




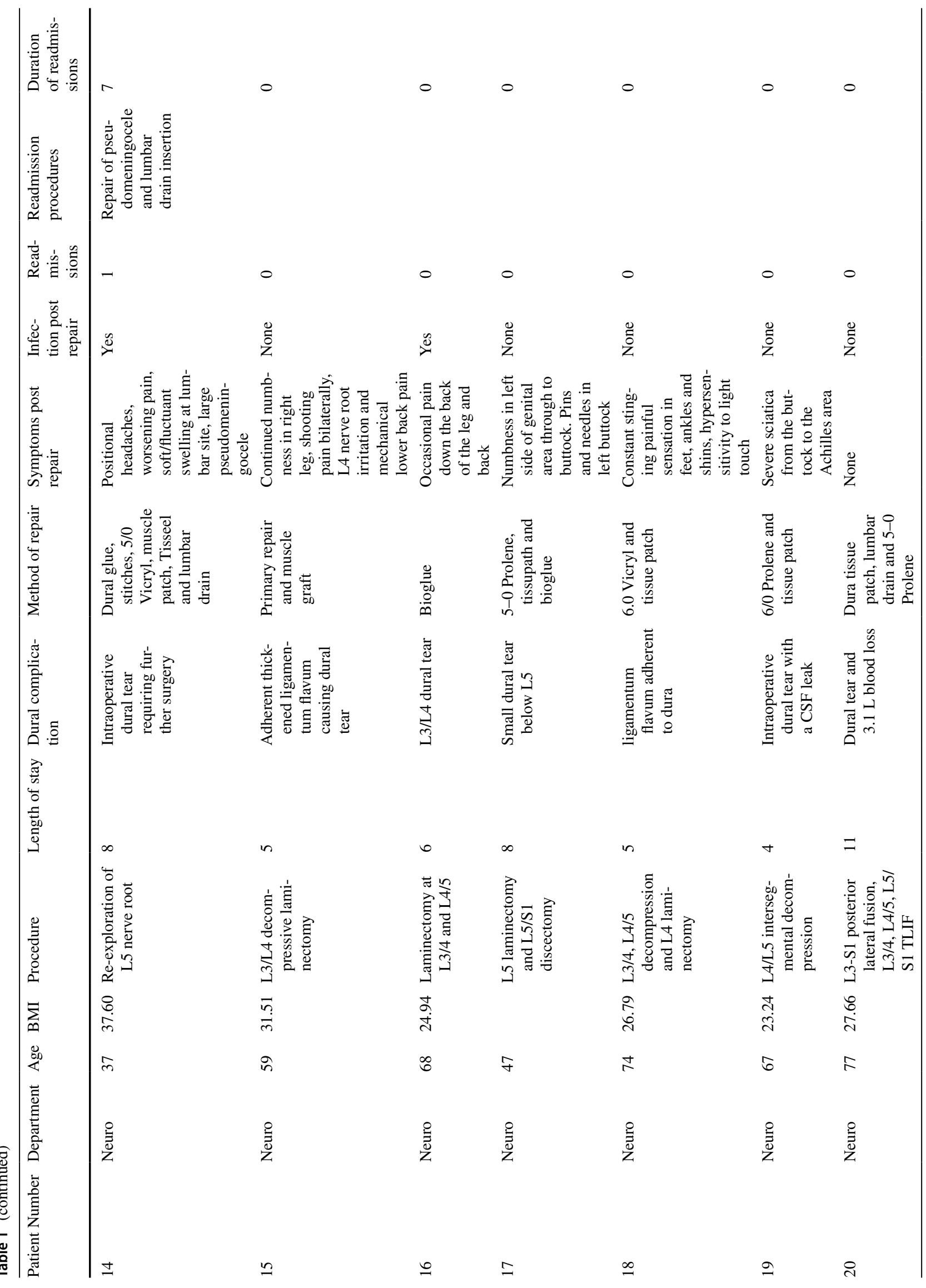




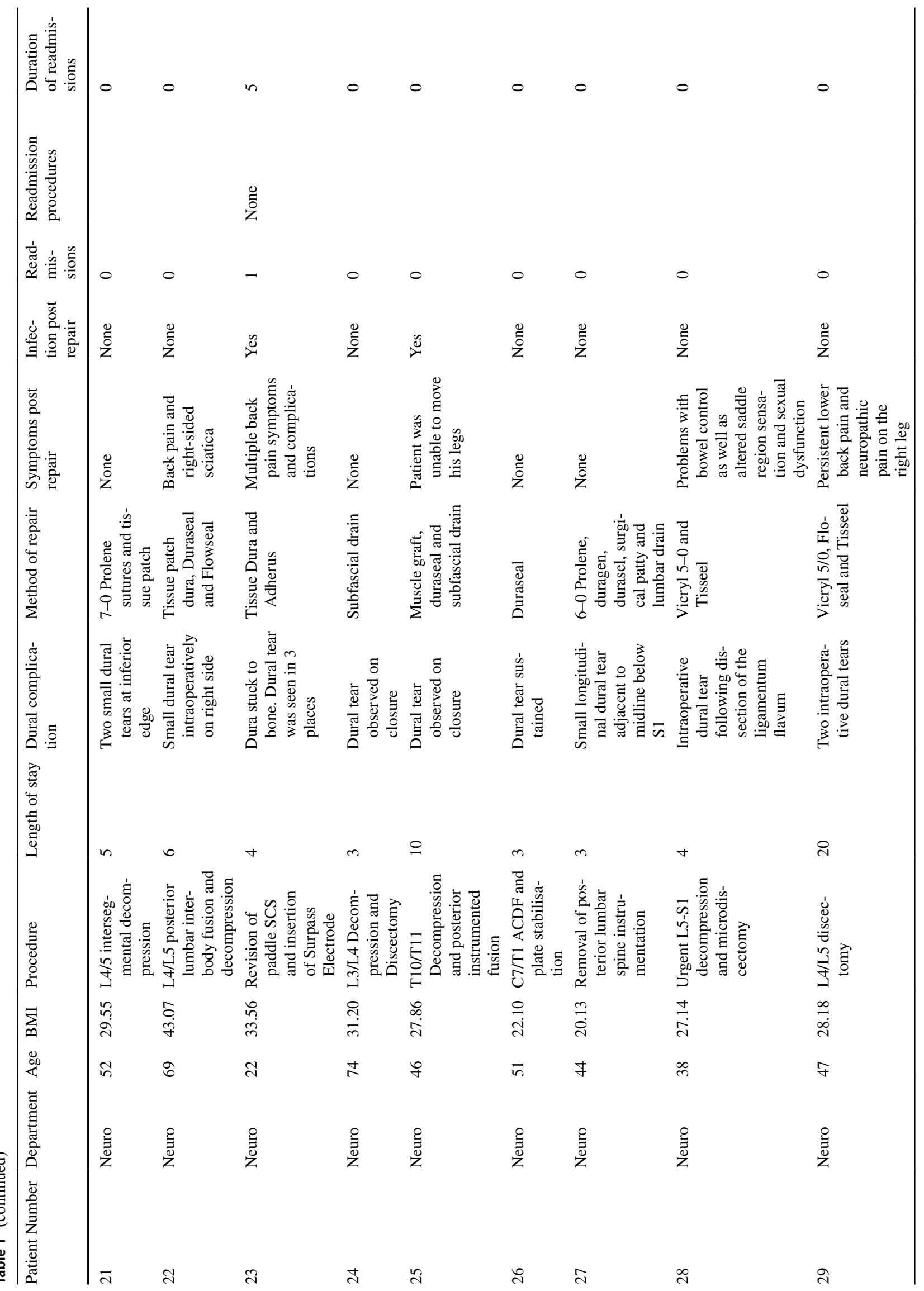




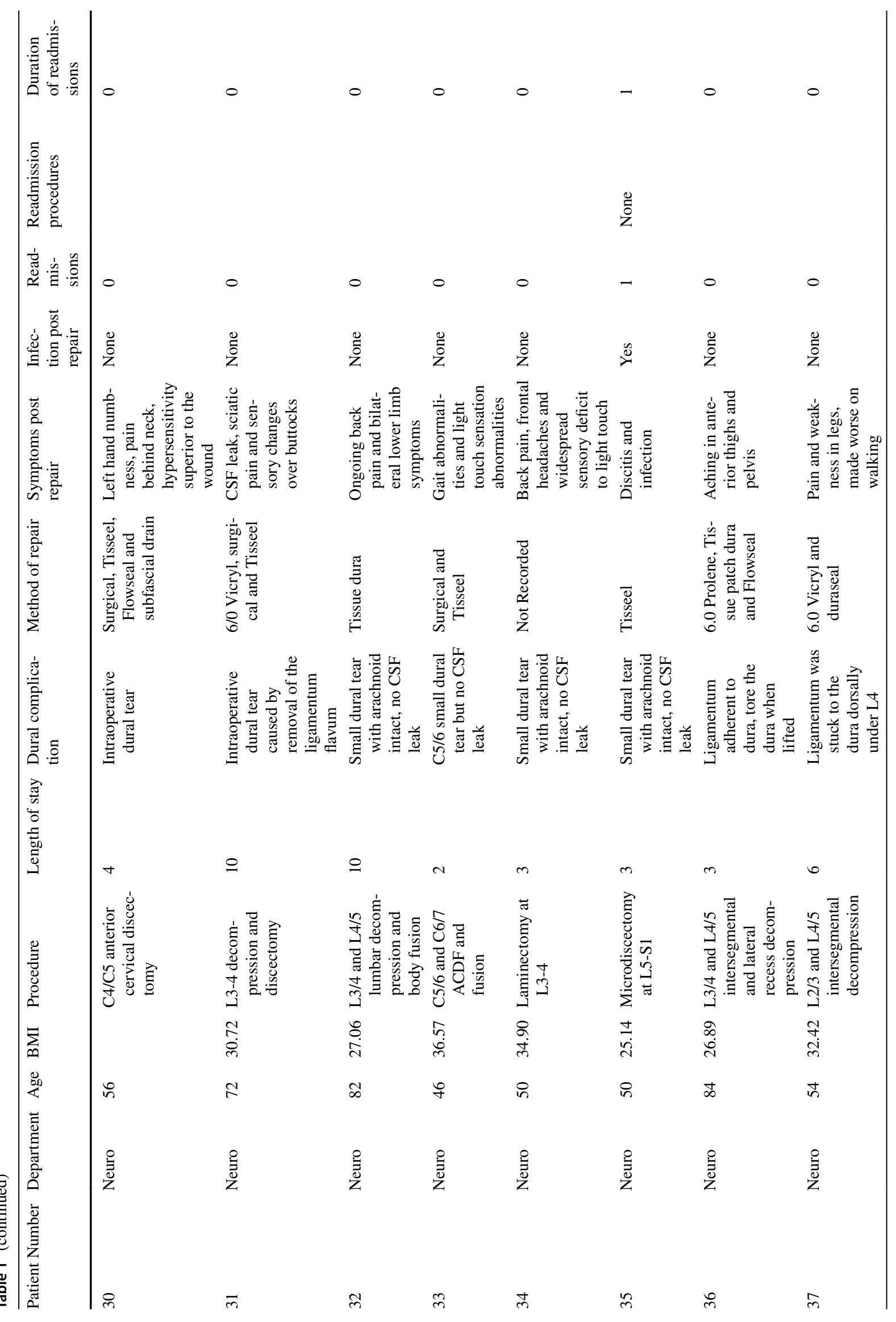




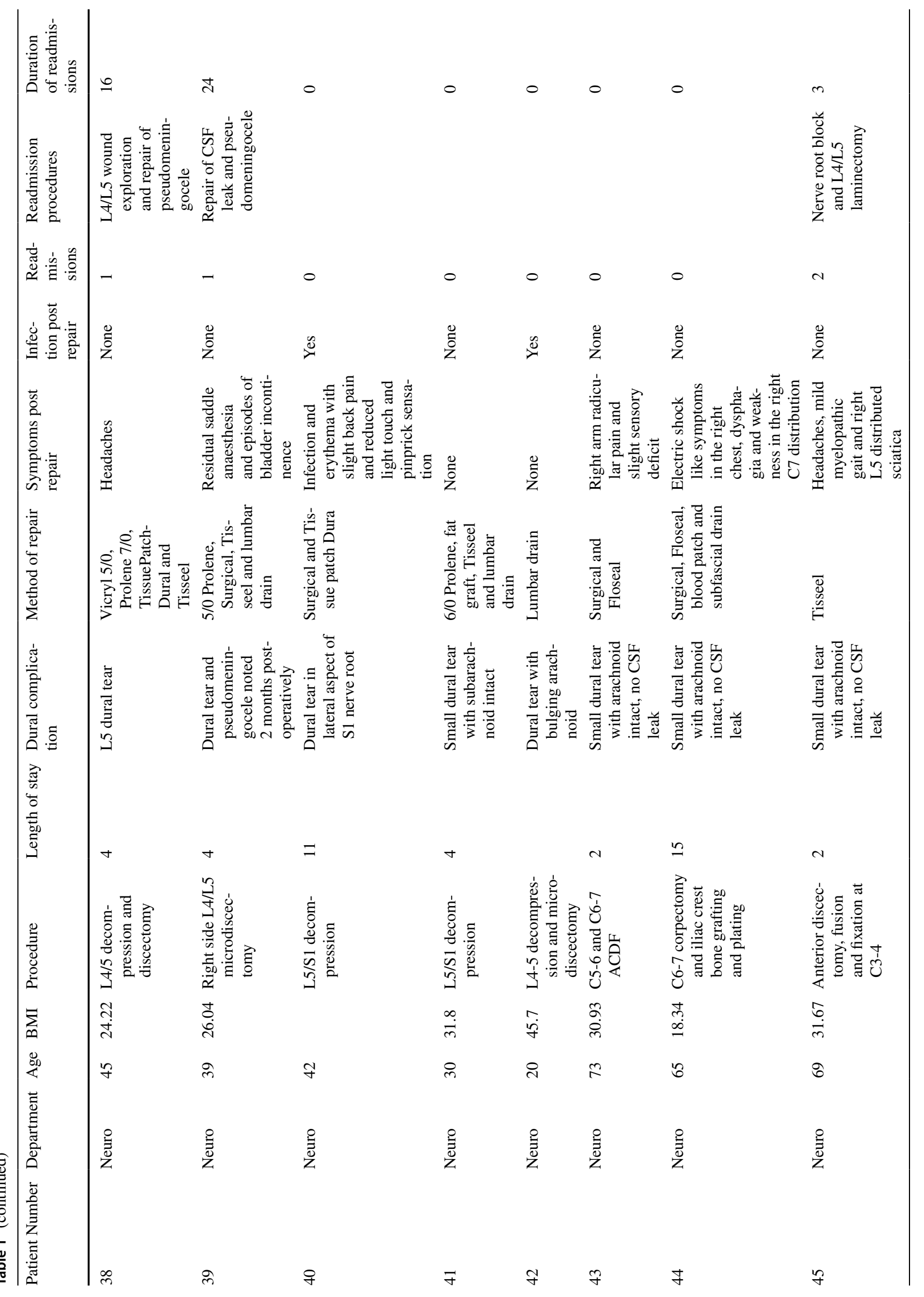




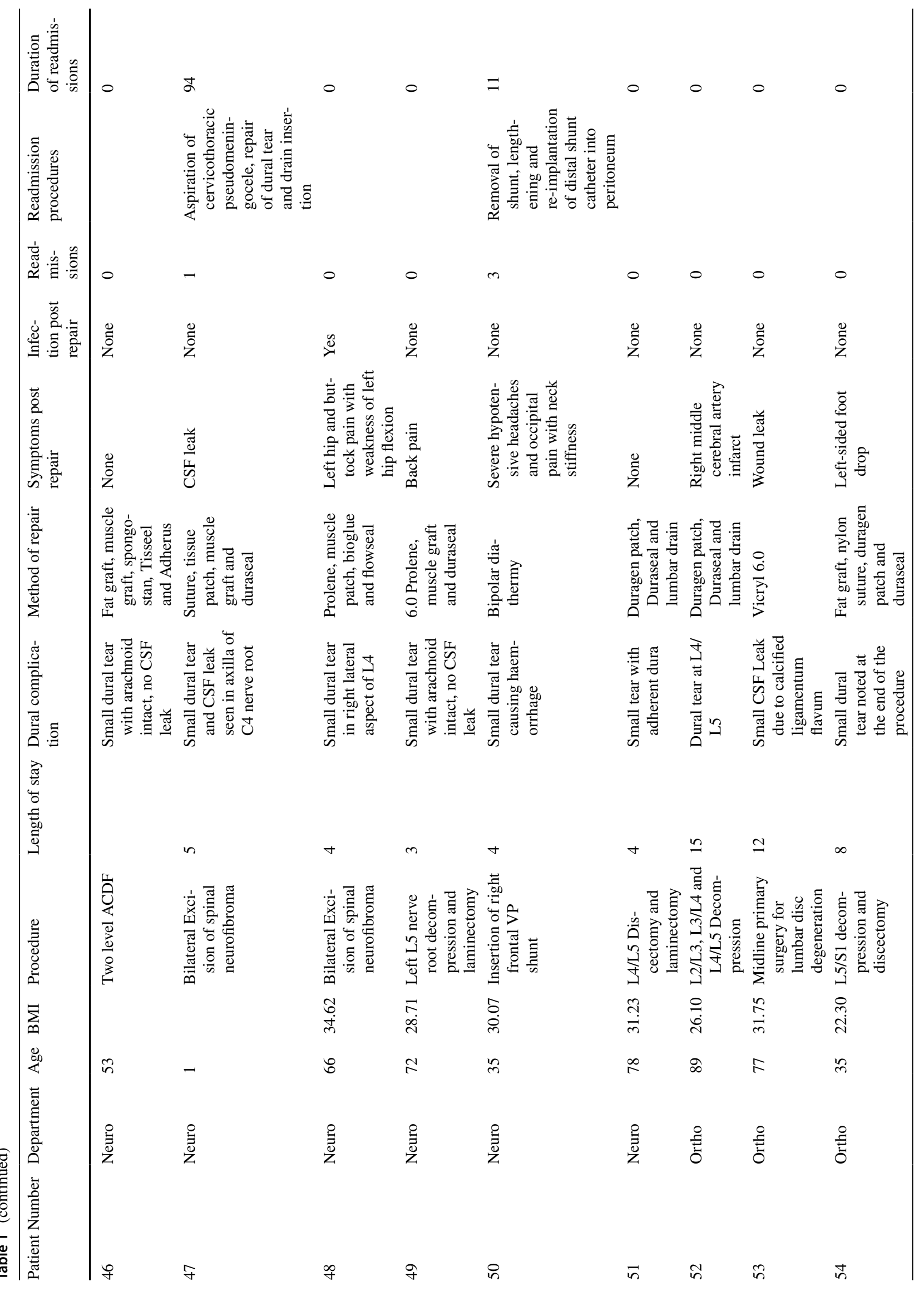




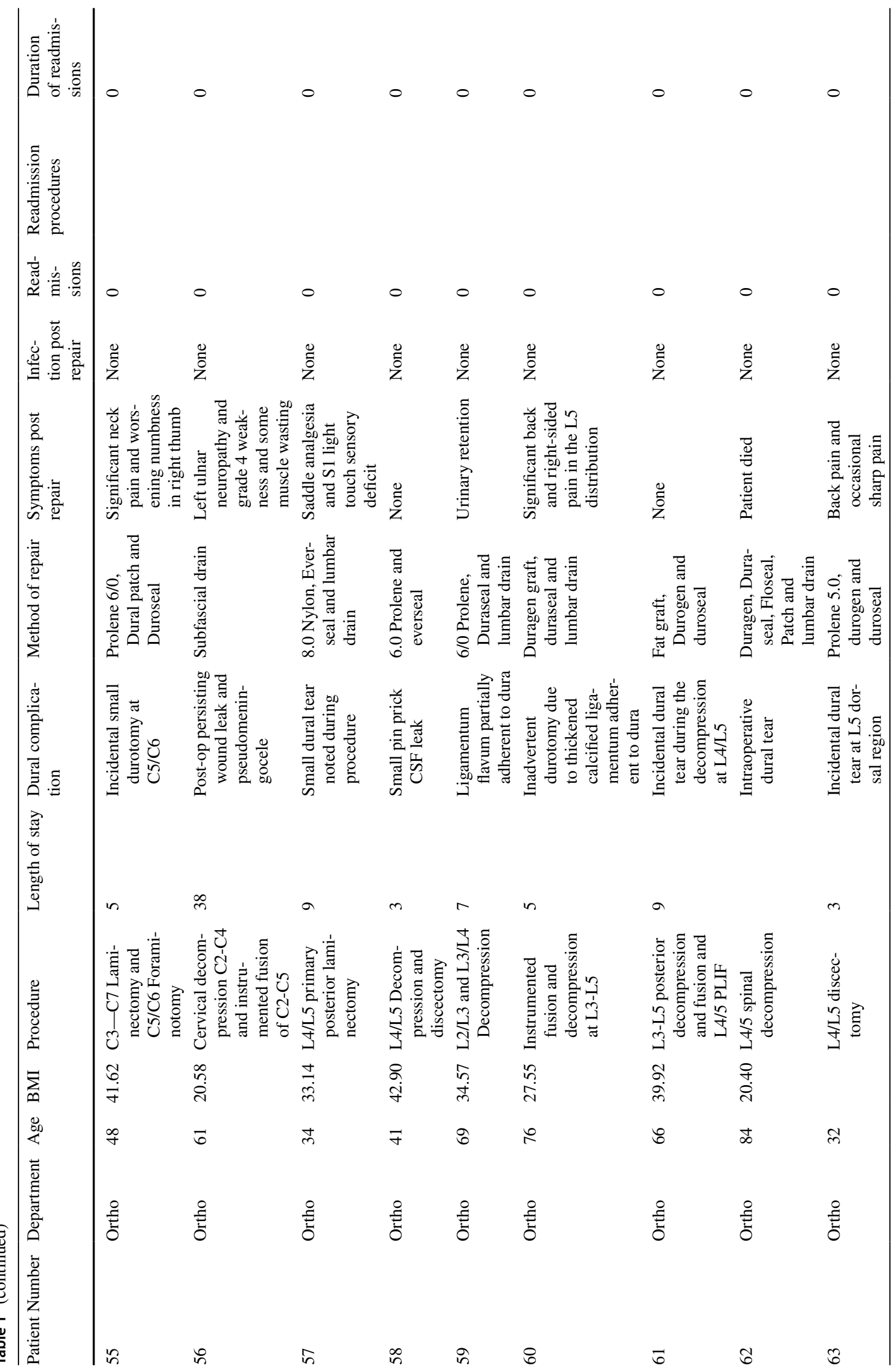




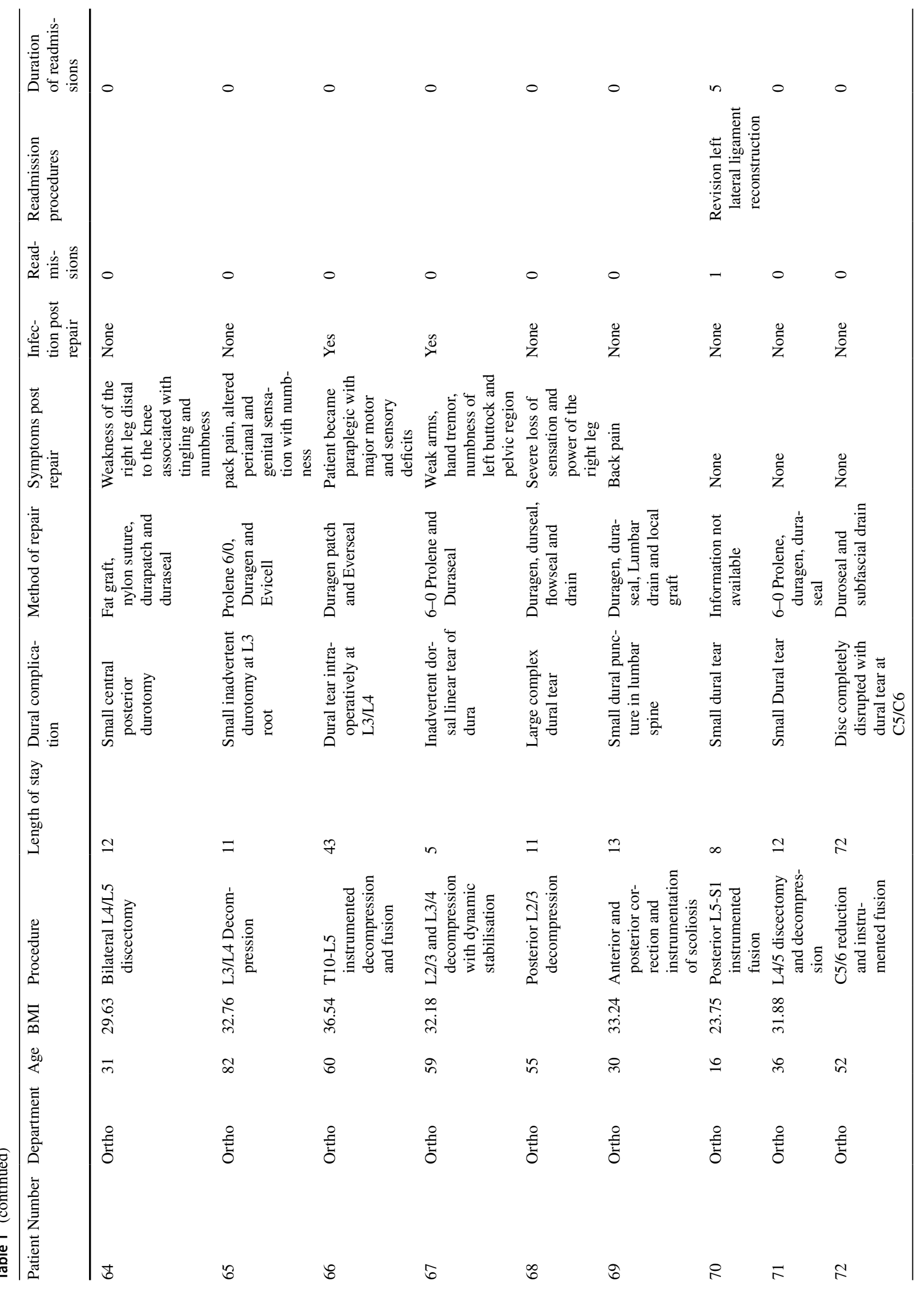




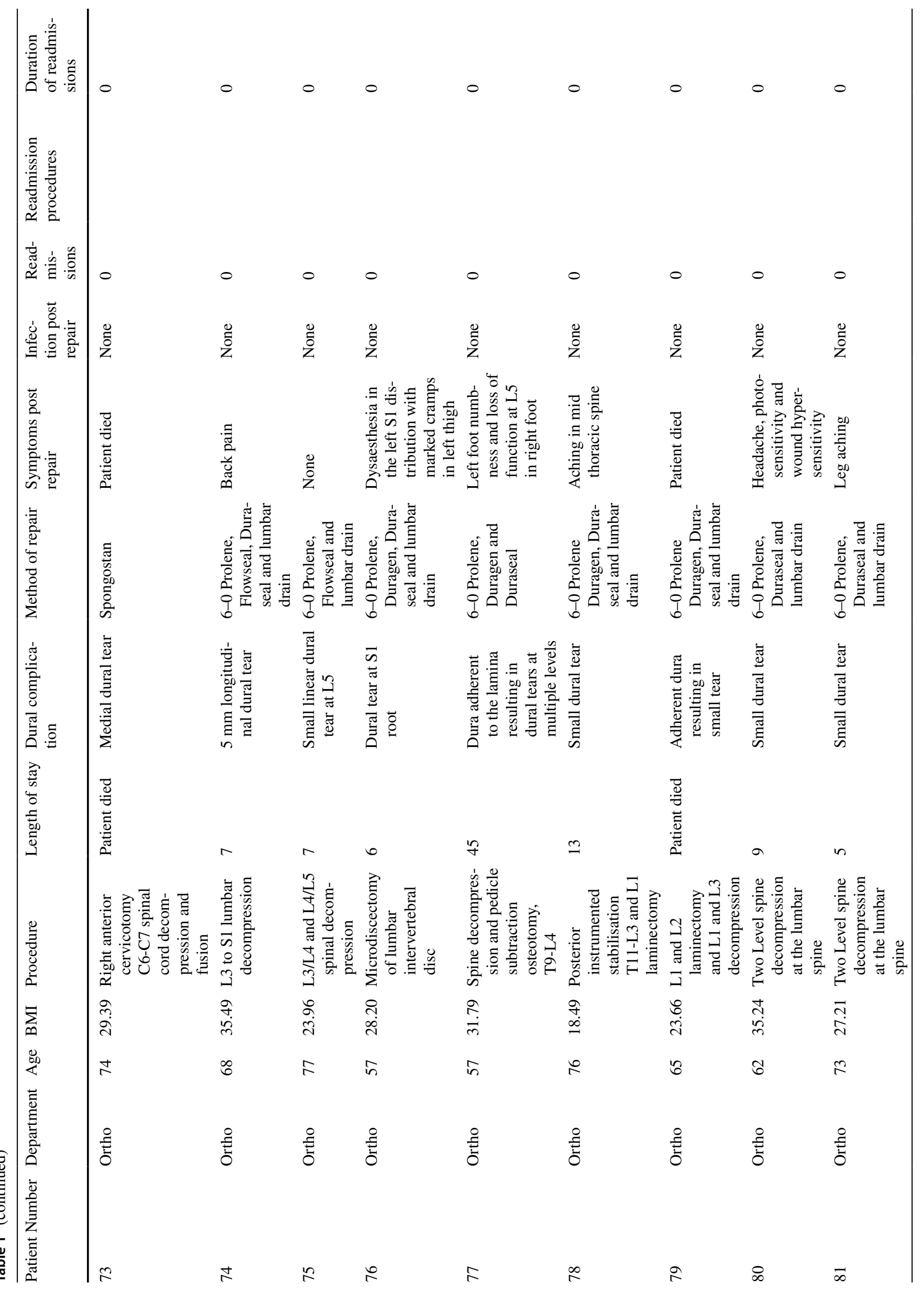




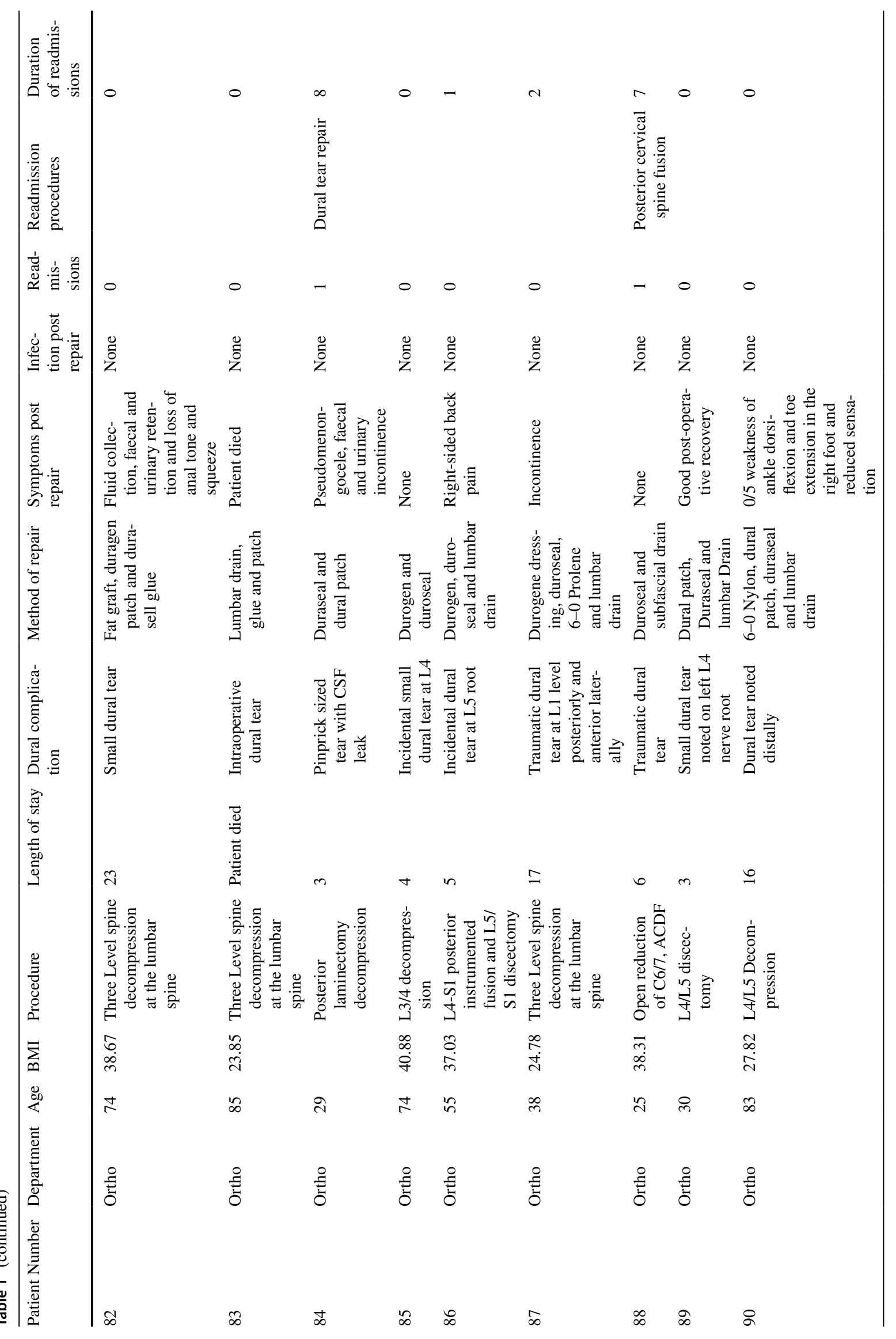




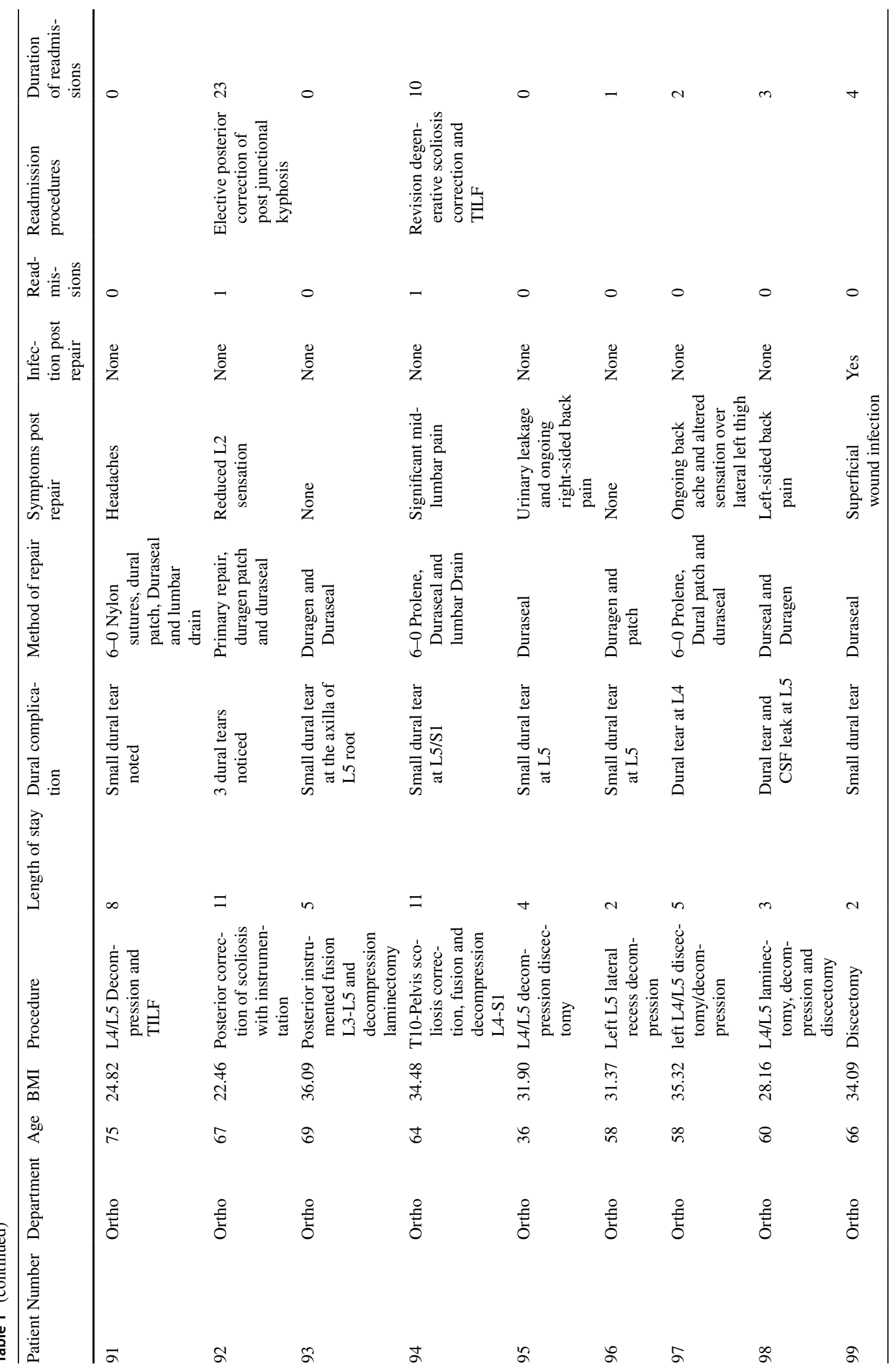




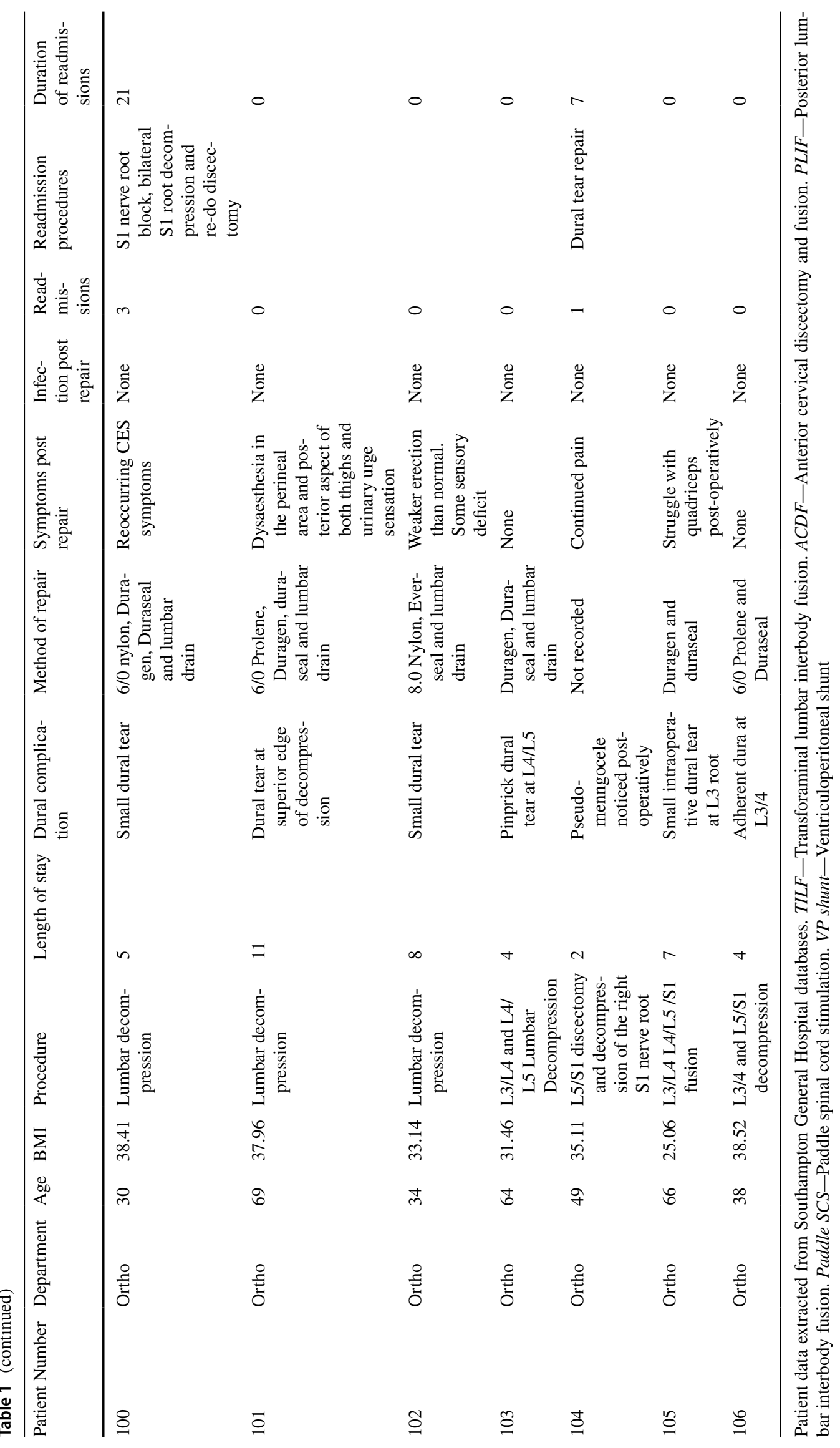


Table 2 Repair method grouping

\begin{tabular}{|c|c|c|}
\hline Group number percentage & $\begin{array}{l}\text { Number of patients } \\
\text { (n) }\end{array}$ & $\begin{array}{l}\text { Percentage } \\
\text { of patients } \\
(\%)\end{array}$ \\
\hline Primary closure alone & 1 & 0.94 \\
\hline Primary closure and artificial patch & 4 & 3.77 \\
\hline Primary closure and autologous patch & 3 & 2.83 \\
\hline Primary closure and sealant & 7 & 6.60 \\
\hline Primary closure and drain & 1 & 0.94 \\
\hline Primary closure, sealant and drain & 11 & 10.4 \\
\hline Primary closure, sealant and artificial patch & 10 & 9.43 \\
\hline Primary closure, sealant, artificial patch and drain & 10 & 9.43 \\
\hline Primary closure, sealant and autologous patch & 6 & 5.66 \\
\hline Primary closure, sealant and autologous patch and drain & 2 & 1.89 \\
\hline Primary closure, sealant, artificial patch and autologous patch & 2 & 1.89 \\
\hline Primary closure, artificial patch and drain & 2 & 1.89 \\
\hline Autologous patch and sealant & 1 & 0.94 \\
\hline Autologous patch and drain & 1 & 0.94 \\
\hline Sealant alone & 9 & 8.49 \\
\hline Sealant and drain & 3 & 2.83 \\
\hline Sealant and artificial patch & 9 & 8.49 \\
\hline Sealant, artificial patch and drain & 8 & 7.55 \\
\hline Sealant and autologous patch & 1 & 0.94 \\
\hline Sealant, autologous patch and drain & 2 & 1.89 \\
\hline Sealant, artificial patch and autologous patch & 2 & 1.89 \\
\hline Artificial patch alone & 2 & 1.89 \\
\hline Drain alone & 4 & 3.77 \\
\hline Unknown & 5 & 4.72 \\
\hline Total & 106 & 100 \\
\hline
\end{tabular}

following round two. Final answers were averaged to give an MCID for each outcome:

1. Length of hospital stay: $\leq 3$ days.

2 . Rate of readmissions or revision surgeries: $<2$ readmissions or revision surgeries.

3. Length of additional admission(s): $\leq 7$ days.

4. Infection rate: No infection present.

5. Neurological symptoms: $\leq 3$-point score.

Benefit rate (patients surpassing MCID/total patients) was calculated for each MCID outcome and reported as a percentage improvement (benefit rate of interventionbenefit rate of the control) (Table 3 ).

\section{Incidence rate}

Descriptive statistics were used to identify the surgery and spinal level with the greatest incidence of tears.

\section{Patient demographics}

Two MANOVAs were conducted against BMI and age for the five outcomes. Patients were grouped into the following age categories: 1-10, 11-20, 21-30, 31-40, 41-50, 51-60, 61-70, 71-80 and 81-90. Patients were grouped into the following BMI categories: Underweight (16.00-18.49), healthy weight (18.50-24.99), overweight (25.00-29.99), moderately obese (30.00-34.99), severely obese (35.00-39.99), very seriously obese (40.00-44.99) and morbidly obese (45.00-49.99).

\section{Type of repair method}

Patients were grouped as per their repair method as shown in Table 2. Repair groups were compared via MANOVA of the five outcome measures. Neurological symptoms are scored as per Table 4 . 
Table 3 MCID percentage improvement analysis for artificial vs autologous patches in conjunction with primary closure

\begin{tabular}{|c|c|c|c|c|c|}
\hline Category & $\begin{array}{l}\text { length of original } \\
\text { stay }\end{array}$ & Infection & Readmissions & $\begin{array}{l}\text { Length of addi- } \\
\text { tional stays }\end{array}$ & Symptoms \\
\hline \multicolumn{6}{|l|}{ Group 1: Artificial patch } \\
\hline Patient & 5 & 0 & 0 & 0 & 4 \\
\hline Patient & 4 & 0 & 0 & 0 & 1 \\
\hline Patient & 5 & 0 & 0 & 0 & 0 \\
\hline Patient & 7 & 0 & 0 & 0 & 3 \\
\hline Number passed MCID & 4 & 4 & 4 & 4 & 3 \\
\hline Number not passed MCID & 0 & 0 & 0 & 0 & 1 \\
\hline Benefit rate (number passed/total number) & $100 \%$ & $100 \%$ & $100 \%$ & $100 \%$ & $75 \%$ \\
\hline \multicolumn{6}{|l|}{ Group 2: Autologous patch } \\
\hline Patient & 3 & 0 & 1 & 7 & 2 \\
\hline Patient & 5 & 0 & 0 & 0 & 5 \\
\hline Patient & 3 & 0 & 1 & 8 & 1 \\
\hline Number passed MCID & 2 & 3 & 1 & 2 & 2 \\
\hline Number not passed MCID & 1 & 0 & 2 & 1 & 1 \\
\hline Benefit rate (number passed/total number) & $67 \%$ & $100 \%$ & $33 \%$ & $67 \%$ & $67 \%$ \\
\hline Percentage improvement & 33 & $\mathbf{0}$ & 67 & 33 & 8 \\
\hline
\end{tabular}

Table 4 Scoring for neurological symptoms

\begin{tabular}{ll}
\hline Symptoms scoring 1 & Symptoms scoring 2 \\
\hline Headache & Fistula formation \\
Nausea & Pseudomeningocele \\
Vomiting & Meningitis \\
Stiffness or tightness across the neck or back & Abscesses \\
Mild sensory disturbances & Arachnoiditis \\
Temporary loss of power & Severe shooting pain \\
Radicular pain & Sciatica \\
Dizziness & Bladder, bowel or \\
& sexual problems \\
Diplopia & \\
Tinnitus & \\
Fluid leak/collection & \\
Vertigo & \\
\hline
\end{tabular}

\section{Primary \pm patch vs non-primary \pm patch}

A MANOVA and series of independent samples t-tests were use against the five outcome measures between patients that received primary closure \pm a patch vs non-primary closure \pm a patch. MCID percentage improvement was calculated.

\section{Artificial vs Autologous patches}

Artificial patches and autologous patches in conjunction with primary closure were compared against each outcome via independent t-tests. MCID percentage improvement was calculated.

\section{Results}

A total of 106 patients sustained an intraoperative tear across the 46 months. Of the included patients, $51(47.7 \%)$ belonged to the neurosurgery department and $55(51.4 \%)$ belonged to Orthopaedics department.

\section{Incidence rate}

1,824 spinal operations were identified in the date range, giving an incidence rate of $5.81 \%$. Of the 106 tears, $43.40 \%$ (46) were caused during L4/L5 operations and $72.64 \%$ (77) were caused during L3-S1 operations. 44\% (47) of tears were elective surgeries, and 56\% (59) were emergency surgeries.

\section{Age}

The average age was $55.3(\mathrm{SD}=18.10$, Min: 1, Max: 89). MANOVA analysis indicated that age has a statistically significant impact on the post-operative outcomes (F (40, $360.224)=5.287, p<0.000$; Wilk's $\Lambda=0.134$, partial $\left.\eta^{2}=0.331\right)$. Infection was most common in the 41-50 and 61-70 age group. 


\section{BMI}

The average BMI was 30.54 ( $\mathrm{SD}=6.00$, Min: 18.34 , Max: $45.70) .60 .71 \%$ of patients were overweight or moderately obese, and only $13.10 \%$ were of a healthy weight. BMI did not have a significant impact on post-operative outcomes, $(\mathrm{F}(25,276.400)=0.685, p=0.870 ;$ Wilk's $\Lambda=0.800$, partial $\left.\eta^{2}=0.44\right)$.

Readmissions and rate of revision surgeries were greatest in the moderately obese $(M=0.41, \mathrm{SD}=0.747)$ and severely obese $(M=0.64, \mathrm{SD}=1.082)$ categories. Infections were only present in the overweight $(M=0.12, \mathrm{SD}=0.332)$, moderately obese $(M=0.15, \mathrm{SD}=0.362)$ and severely obese $(M=0.14, \mathrm{SD}=0.363)$ and neurological symptom severity generally increased with BMI.

\section{Type of repair method}

Primary closure, sealant and a lumbar drain was the most common repair technique $10.4 \%(n=11)$. Primary closure was used in $55.7 \%$ of cases $(n=59)$. However, combinations of sealants, patch's, lumbar and subfascial drains without any form of primary closure were also commonly opted for $(32.1 \%(n=34))$. Figure 2 illustrates the frequency of use of each method.
Following MANOVA, no significant difference in the five outcomes was observed between all repair methods $(\mathrm{F}(105,342.101)=0.793, p=0.921$; Wilk's $\Lambda=0.345$, partial $\left.\eta^{2}=0.192\right)$.

\section{Primary $\pm a$ patch vs all other repair methods}

When comparing primary closure \pm a patch $(n=7)$ against all other forms of repair $(n=99)$, primary closure \pm a patch scored better in $4 / 5$ clinical outcomes:

1. Length of original stay was over 3.5 days shorter $(M=4.57, \mathrm{SD}=1.40$ vs $M=8.58, \mathrm{SD}=10.16, p>0.05)$. $4 \%$ MCID percentage improvement.

2. The rate of additional admissions/surgeries was almost half $(M=0.29, \mathrm{SD}=0.49$ vs $M=0.41, \mathrm{SD}=0.805$ $p>0.05) .27 \%$ MCID percentage improvement.

3. Length of additional stays was on average 1.35 days less $(\mathrm{M}=2.14, \mathrm{SD}=3.671$ vs $M=3.45, \mathrm{SD}=11.43$ $p>0.05)$. No MCID percentage improvement $(-2 \%)$.

4. Infection rate post-operatively was 0 for the primary repair \pm patch group $(\mathrm{M}=0.00, \mathrm{SD}=0.000)$ and 0.11 in all other treatment groups $(M=0.12, \mathrm{SD}=0.328$, $p>0.05) .12 \%$ MCID percentage improvement.

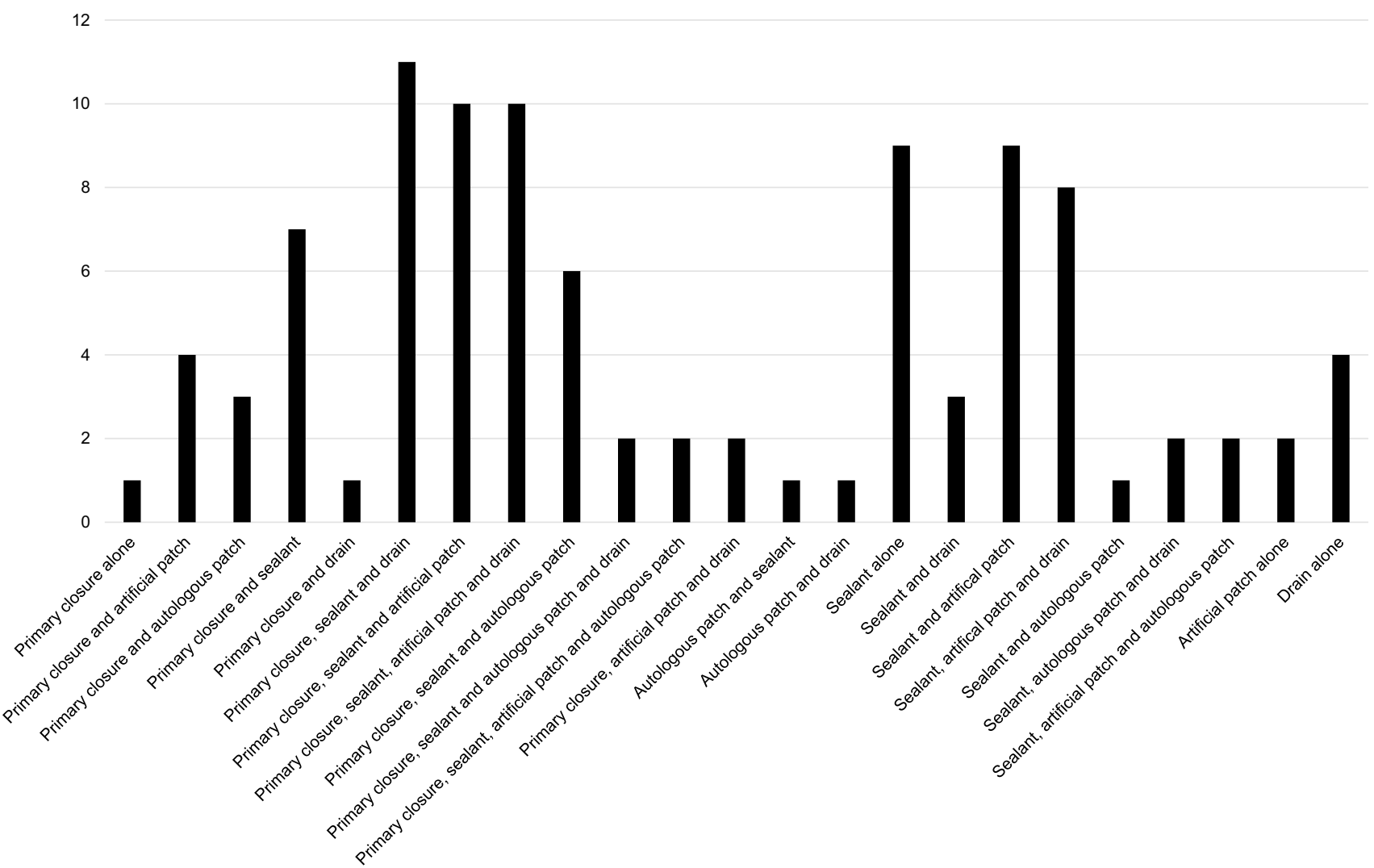

Fig. 2 Bar graph displaying dural tear repair methods used and the frequency of each methods use 
5. Severity of neurological symptoms was slightly greater in the primary repair \pm patch group $(M=2.29$, $\mathrm{SD}=1.799$ vs $M=1.78, \mathrm{SD}=1.59)$, this was reflected by an MCID of $-14 \%$.

Following a MANOVA of primary closure \pm a patch, no significant difference was observed (F (5, 89) $=0.559, p=0.731$; Wilk's $\Lambda=0.97$, partial $\left.\eta^{2}=0.197\right)$.

\section{Artificial vs autologous patches}

When comparing artificial patches and autologous patches in conjunction with primary closure, no significant difference was seen in the length of original stay $(M=3.67, \mathrm{SD}=1.155$ vs $M=5.25, \mathrm{SD}=1.258, p>0.05$ ).

No patient in the artificial group required further admission or surgery, however, two patients in the autologous group $\operatorname{did}(\mathrm{M}=0.00, \mathrm{SD}=0.000$ vs $\mathrm{M}=0.67, \mathrm{SD}=0.577$, $p>0.05)$. This equated to a $67 \%$ MCID improvement. Due to no patients in the artificial patch group requiring further admission the artificial patch group had a 33\% MCID improvement in the length of further admission(s) $(M=0.00$, $\mathrm{SD}=0.000$ vs $M=5.00, \mathrm{SD}=4.359, p>0.05$ ).

No difference in infection rate between the two groups was observed as no patients in either groups sustained an infection (M0.00, $\mathrm{SD}=0.00$ and $M=0.00, \mathrm{SD}=0.00$ ). However, the artificial group experienced less severe neurological symptoms post-operatively (M2.00, $\mathrm{SD}=1.826$ vs $M=2.67$, $\mathrm{SD}=2.08)$, with an $8 \%$ MCID improvement.

\section{Discussion}

An incidental durotomy refers to the intraoperative tearing of the outer most layer of the meninges [1]. The incidence rate of dural tears shows considerable inter-study variation dependent on the type of procedure, pathology and re-operative rate [7-11]. Owing to the increasing complexity of spinal procedures the rate of dural tears is increasing and they continue to be a common surgical complication [8]. Our incidence rate of $5.81 \%$ falls within the reported range of $1-17 \%[12,13]$ and supports the literature theme that such tears most commonly occur at the lumbar spine with $72.64 \%$ of the 106 tears occurring between L3-S1 [8].

Further to their common occurrence, dural tears are associated with a range of side effects including fistula formation, meningitis and more commonly orthostatic low-pressure headaches $[10,13,14]$. The most common side effects reported in this study were low-pressure headaches, stiffness across the back and CSF leak.

Despite these side effects, the long-term implications of incidental durotomies is disputed $[15,16]$ as is the most suitable method for repair. Whilst, primary repair is generally considered a suitable management strategy [10], some studies have concluded that it may not be essential for successful management $[13,17]$ whilst others report the contrary [10]. Equally, there is little comparative data regarding patient outcomes associated with combinations of repair methods and the repair combinations commonly opted for.

In this study, patients were grouped per their specific repair method and compared against the five clinical outcomes. Further analysis using the same outcomes were conducted on patient age, BMI and on the use of primary closure and type of dural patches used. Minimal clinically important difference was reported according to the Delphi method [18, 19]

Our study demonstrated that when considering these five outcomes, the age of a patient has a significant impact post-operatively. Based on previously published research and the patients included within this study, this finding was suspected to be a result of generalised increased morbidity due to prolonged hospital stay and poorer wound healing as well as more complex initial operative indications within the more elderly patients [20, 21]. Despite BMI not having a significant impact, the rate of readmissions, revision surgeries and infection rate increased with BMI. Complications associated with bariatric spinal patients are well documented [22-24]; therefore, highlighting the significance that $60.71 \%$ of the patients were either overweight or moderately obese.

Primary closure, sealant and a lumbar drain was the most common repair method. However, despite primary closure being considered the gold standard [6, 10], it was only used in $55.7 \%$ of cases $(n=59)$. The sample size and grouping of patients resulted in each group containing a small number of patients which likely contributed to non-significant MANOVA results. However, the use of primary closure with or without a patch was shown to be superior in four out of the five of the outcomes. These data show that primary closure \pm patch generates on average a shorter initial stay in hospital (4\% MCID improvement), a reduced rate of readmission or need for additional surgeries (27\% MCID improvement), a shorter readmission period (No MCID percentage improvement) and a lower infection rate (12\% MCID percentage improvement). 'Future research may benefit by comparing the outcomes in a homogenous patient sample between those who received no drain, a subfascial drain or a lumbar drain as part of their tear management. Each type drain cannot be considered as equal and therefore an inter-drain outcome comparisons should be made'.

In recent years, synthetic patches such as a collagen matrix or gelatin sponge have received US Food and Drug Administration approval for use in the repair of a dural tears. This approval provided a growing alternative to the more traditionally used autologous fat, muscle and fascia based patches [25]. Previously opted for autologous patches have reported success rates as low as $70 \%$ when 
performed within $24 \mathrm{~h}$ of a dural tear [26] and speculative evidence suggests that artificial patches may be better suited to adapt to all defects as they are more readily available, can be cut to shape and may achieve watertight closure in a possibly shorter operative time [25, 27]. Additionally, artificial grafts may display further benefits through their chemotactic interaction with dural fibroblasts [28]. However, there is little direct research between artificial and autologous patches and consequentially no consensus on which material is best.

Within this study, when comparing artificial and autologous patches in conjunction with primary closure, artificial patches resulted in shorter hospital admission (33\% MCID percentage improvement), lower rates of readmission/need for revision surgeries (67\% MCID percentage improvement) and shorter length of additional stays (33\% MCID percentage improvement) as well as less severe neurological symptoms post-operatively (8\% MCID percentage improvement). This is contrary to the results of Sabatino G, et al. [29] and Abla AA, et al. [30] who both reported no difference when comparing autologous and non-autologous grafts.

\section{Conclusions}

This study reports an incidental durotomy rate of $5.81 \%$ in a total of 106 patients from Southampton General Hospital's Neurosurgical and Orthopaedics departments. In accordance with the current literature, $72.64 \%$ were sustained at the L3-S1 spinal level.

In this study, age was shown to have a significant impact on post-operative outcomes and BMI displayed positive correlation with the rate of readmissions, revision surgeries and post-operative infection. No significant difference was observed between repair groups; however, primary closure \pm a patch scored better in $4 / 5$ clinical outcomes when compared to other forms of repair.

The use of primary closure, a sealant and a lumbar drain was the most commonly opted for repair method and primary was used in only $55.7 \%$ of cases. Further analysis showed that artificial patches in conjunction with primary closure achieved lower rates of readmission/need for revision surgery and shorter length of additional hospital stays as well as less severe neurological symptoms post-operatively than autologous patches.

This study highlights the importance of age and BMI on post-operative dural tear outcomes and supports the use of primary closure \pm a patch. This study also provides limited evidence in favour of artificial over autologous patches and recommends that dural patches always be used in conjunction with primary closure.

\section{Limitations}

The limited data that could be obtained retrospectively restricted analysis to only five outcomes and the small sample size and patient grouping resulted in several groups containing a limited numbers of patients. The study analysis was also dependent on the accuracy of operative notes. Primary limitations of this study therefore include its retrospective method of data acquisition, small sample size, considerable patient and operative heterogenicity and reliance on the accuracy of operative procedural notes. It is important to note that clinical heterogenicity arose from differing preoperative diagnoses, type of procedure, duration of follow up and method of wound closure which due to insufficient data are unreported in this study. However, despite these causes of heterogenicity, the authors believe that the present study adequately addresses its primary aim of comparing all current methods of iatrogenic dural tear repair surgery across a variety of clinical scenarios and operative indications. This study should therefore serve as a generalizable and more widely applicable attempt to evaluate the most effective dural tear repair method in a boarder operative context. Future research should further define individual patient populations to subsequently eliminate causes of clinical heterogenicity. However, such studies must follow prior nonexclusive research.

Finally, it cannot be certain as to whether the reported neurological deficits in the study were the consequence of the dural tear or the primary surgical procedure. Despite these limitations, the authors believe that this study provides an important overall and generalised evaluation of dural tear repair methods and raises several questions on a clinically and scientifically important topic of spinal surgery.

Authors' contributions All authors contributed equally to the research conceptualisation and to the acquisition, analysis and interpretation of data. Data analysis and manuscript preparation were performed by $\mathrm{CT}$ and AK. All authors commented on previous versions of the manuscript and to the final version and agree to be accountable for all aspects of the work.

Funding No funds, grants, or other support was received.

Data availability All data generated or analysed during this study are included in this published article.

\section{Declarations}

Conflict of interests The authors declare that they have no conflict of interests.

Ethical approval Ethical approval was waived by the local Ethics Committee of The University of Southampton in view of the retrospective nature of the study and all the procedures being performed were routine care. 
Open Access This article is licensed under a Creative Commons Attribution 4.0 International License, which permits use, sharing, adaptation, distribution and reproduction in any medium or format, as long as you give appropriate credit to the original author(s) and the source, provide a link to the Creative Commons licence, and indicate if changes were made. The images or other third party material in this article are included in the article's Creative Commons licence, unless indicated otherwise in a credit line to the material. If material is not included in the article's Creative Commons licence and your intended use is not permitted by statutory regulation or exceeds the permitted use, you will need to obtain permission directly from the copyright holder. To view a copy of this licence, visit http://creativecommons.org/licenses/by/4.0/.

\section{References}

1. Kalevski SK, Peev NA, Haritonov DG (2010) Incidental dural tears in lumbar decompressive surgery: incidence, causes, treatment, results. Asian J Neurosurg 5:54-59

2. Sin AH, Caldito G, Smith D, Rashidi M, Willis B, Nanda A (2006) Predictive factors for dural tear and cerebrospinal fluid leakage in patients undergoing lumbar surgery. J Neurosurg Spine 5:224-227

3. Espiritu MT, Rhyne A, Darden BV (2010) 2nd Dural tears in spine surgery. J Am Acad Orthopae Surgeons 18:537-545

4. Wolff S, Kheirredine W, Riouallon G (2012) Surgical dural tears: prevalence and updated management protocol based on 1359 lumbar vertebra interventions. Orthopaed Traumatol, Surg Res 98:879-886

5. Epstein NE (2013) A review article on the diagnosis and treatment of cerebrospinal fluid fistulas and dural tears occurring during spinal surgery. Surg Neurol Int 4:S301-S317

6. Dafford EE, Anderson PA (2015) Comparison of dural repair techniques. Spine J: Official J North Am Spine Soci 15:1099

7. Kalevski S, Peev N, Haritonov D (2010) Incidental dural tears in lumbar decompressive surgery: Incidence, causes, treatment, results. Asian J Neurosur 5:54

8. Bosacco SJ, Gardner MJ, Guille JT (2001) Evaluation and treatment of dural tears in lumbar spine surgery: a review. Clinical Orthopaed Related Res 389:238-247

9. Tafazal SI, Sell PJ (2005) Incidental durotomy in lumbar spine surgery: incidence and management. Eur Spine J 14:287-290

10. Guerin P, El Fegoun AB, Obeid I, Gille O, Lelong L, Luc S, Bourghli A, Cursolle JC, Pointillart V, Vital J-M (2012) Incidental durotomy during spine surgery: incidence, management and complications. A retrospective review Injury 43:397-401

11. Cammisa FP Jr, Girardi FP, Sangani PK, Parvataneni HK, Cadag S, Sandhu HS (2000) Incidental durotomy in spine surgery. Spine 25:2663-2667

12. Shahin Y, Kett-White R (2010) Incidence of dural tears post lumbar spine surgery. In: Orthopaedic Proceedings. The British Editorial Society of Bone \& Joint Surgery. pp. 239-239

13. Grannum S, Patel MS, Attar F, Newey M (2014) Dural tears in primary decompressive lumbar surgery. Is primary repair necessary for a good outcome? Eur Spine J 23:904-908

14. Saxler G, Krämer J, Barden B, Kurt A, Pförtner J, Bernsmann K (2005) The long-term clinical sequelae of incidental durotomy in lumbar disc surgery. Spine 30:2298-2302

15. Wang JC, Bohlman HH, Riew KD (1998) Dural tears secondary to operations on the lumbar spine. Management and results after a two-year-minimum follow-up of eighty-eight patients. JBJS 80:1728-1732

16. Jones AA, Stambough J, Balderston R, Rothman R, Booth R Jr (1989) Long-term results of lumbar spine surgery complicated by unintended incidental durotomy. Spine 14:443-446

17. Eismont FJ, Wiesel S, Rothman RH (1981) Treatment of dural tears associated with spinal surgery. JBJS 63:1132-1136

18. Black N, Murphy M, Lamping D, McKee M, Sanderson C, Askham J, Marteau T (1999) Consensus development methods: a review of best practice in creating clinical guidelines. J Health Serv Res Policy 4:236-248

19. Copay AG, Subach BR, Glassman SD, Polly DW Jr, Schuler TC (2007) Understanding the minimum clinically important difference: a review of concepts and methods. Spine J 7:541-546

20. Tsutsumimoto T, Yui M, Uehara M, Ohta H, Kosaku H, Misawa $\mathrm{H}$ (2014) A prospective study of the incidence and outcomes of incidental dural tears in microendoscopic lumbar decompressive surgery. The bone \& joint journal 96:641-645

21. Deyo R, Cherkin D, Loeser J, Bigos S, Ciol M (1992) Morbidity and mortality in association with operations on the lumbar spine. The influence of age, diagnosis, and procedure. J Bone Joint Surg Am 74:536-543

22. Patel N, Bagan B, Vadera S, Maltenfort MG, Deutsch H, Vaccaro AR, Harrop J, Sharan A, Ratliff JK (2007) Obesity and spine surgery: relation to perioperative complications. J Neurosurg Spine 6:291-297

23. Passias PG, Horn SR, Vasquez-Montes D, Shepard N, Segreto FA, Bortz CA, Poorman GW, Jalai CM, Wang C, Stekas N (2018) Prior bariatric surgery lowers complication rates following spine surgery in obese patients. Acta Neurochir 160:2459-2465

24. Telfeian AE, Reiter GT, Durham SR, Marcotte P (2002) Spine surgery in morbidly obese patients. J Neurosurg Spine 97:20-24

25. Choi EH, Chan AY, Brown NJ, Lien BV, Sahyouni R, Chan AK, Roufail J, Oh MY (2021) Effectiveness of repair techniques for spinal dural tears: a systematic review. World Neurosurg 149:140-147

26. Turnbull D, Shepherd D (2003) Post-dural puncture headache: pathogenesis, prevention and treatment. Br J Anaesth 91:718-729

27. Zenga F, Tardivo V, Pacca P, Garzaro M, Garbossa D, Ducati A (2016) Nanofibrous synthetic dural patch for skull base defects: preliminary experience for reconstruction after extended endonasal approaches. J Neurol Surg Report 2:e50-e55

28. Narotam PK, van Dellen JR, Bhoola KD (1995) A clinicopathological study of collagen sponge as a dural graft in neurosurgery. J Neurosurg 82:406-412

29. Sabatino G, Della Pepa GM, Bianchi F, Capone G, Rigante L, Albanese A, Maira G, Marchese E (2014) Autologous dural substitutes: a prospective study. Clin Neurol Neurosurg 116:20-23

30. Abla AA, Link T, Fusco D, Wilson DA, Sonntag VK (2010) Comparison of dural grafts in Chiari decompression surgery: review of the literature. J Craniovertebral Junction Spine 1:29

Publisher's Note Springer Nature remains neutral with regard to jurisdictional claims in published maps and institutional affiliations. 